\title{
Importance of the Maturity of Photonic Component Industry on the Business Prospects of Optical Access Networks: A Techno-Economic Analysis
}

\author{
Dimitris Varoutas ${ }^{1}$, Thomas Kamalakis ${ }^{1}$, Dimitris Katsianis ${ }^{1}$, Thomas Sphicopoulos ${ }^{1}$, \\ and Thomas Monath ${ }^{2}$ \\ ${ }^{1}$ Department of Informatics and Telecommunications, University of Athens Greece, GR15784 \\ ${ }^{2}$ T-Systems Nova GmbH, Goslarer Ufer 35, D-10589
}

\begin{abstract}
This paper discusses the influence of the maturity of the photonic component industry (PCI) in the business prospects of optical access network deployments. Using the TONIC techno-economic tool, the business prospects of such deployments (in terms of traditional investment indexes such as the Net Present Value - NPV or Internal Rate of Return - IRR) are related to the several factors which characterize the maturity of the PCI such as production volumes and component cost evolution. The analysis shows that even if the cost of Fiber-to-the-Home/Office (FTTH/O) and Fiber-to-the-Curb scenarios are mainly influenced by fiber installation costs, the price reduction rate of photonic components may also affect the investment strategies. To speed up the cost reductions, telecom carriers should therefore invest on optical technology research and development.
\end{abstract}

\section{Introduction}

The photonics era is marked by an unprecedented bandwidth increase in the core and metropolitan area network. Optical technologies are presently migrating towards the customer premises where various scenarios can be considered. In the Fiber-to-theHome/Office scenario, the optical fiber is deployed up to the customer premises. The world leader in FTTH/O is Japan, where the number of subscribers has reached 6 millions and is growing steadily since 2003. Many countries in Europe are also considering FTTH/O in their major cities. However, financial reality often forces telecom carriers to turn to intermediate solutions such as Fiber-to-the-Curb (FTTC) [2]. The business prospects of such large telecom investment projects can be investigated using techno-economic methods and tools. Applying such methodologies, and taking into account the characteristics of European urban areas as well as service demand forecasts, it has been shown than FTTC solutions are indeed much more favorable to FTTH/O [1]. In [3], the historical competitive and economic reasons for the slow deployment of FTTH in the United States market have been analyzed and technical and regulatory proposals have been concluded. In addition to these works, studies on the economic perspectives of specific optical network architectures and technologies have recently appeared 4-7, but they focus mainly in 
analyzing the original installation cost. However, in order to fully understand the business prospects of a telecom investment, many other financial aspects such as Operation, Administration and Maintenance (OA\&M) costs must be taken into account in order to compute revenues and cash flows. Another point to consider is that the costs of the various network components tend to decrease in time as a result of increased production volumes as well as research and innovation.

The PCI is a relatively immature industry compared to the electronic industry. Although integrated optics have made remarkable progress over the years, there are still many barriers preventing the industry to reach electronic-like standards. This is mainly due to the small scale of integration and to the fact that there are still many competing integration platforms (InP, silicon and organic materials). This paper aims to highlight the way in which the maturity of the photonic component industry affects the prospects of hybrid fiber/copper Fiber-To-The (FTTx) access architectures from the operator's point of view. Towards this end, the TONIC techno-economic tool, developed within a series of EU funded projects is used. This methodology have been used to study various upgrade or deployment scenarios for both optical and wireless telecommunication networks $[2,9,10]$. The current version of the tool has been developed within the ISTTONIC (Techno-economics of IP Optimized Networks and Services) project [11] and the CELTIC/ECOSYS (techno-ECOnomics of integrated communication SYStems and services) project [12].

The scenarios studied in this paper are based on either Fiber-To-The Cabinet (FTTC) or Fiber-To-The-Home/Office FTTH/O architectures. These can be implemented using two alternatives: an Asynchronous Transfer Mode (ATM) Passive Optical Network (PON) or an Ethernet-based access network with optical point-topoint connections (Figure 1). As shown in [2] the business prospects of ATM and Ethernet technologies are practically the same in both FTTC and FFTH/O. Using these network infrastructures and defining suitable service and traffic characteristics, the various scenarios are studied over an 8-year period (2003-2010) for different types of metropolitan areas assuming an incumbent operator. The starting year chosen to be 2003 rather than 2006, since in many countries as in Japan, FTTH/O deployments date as back as 2003 and the aim of the paper is to demonstrate how investments in optical technology may also affect FTTH/O and FTTC deployments that have been made as early as that. The discount ratio (reflecting the cost of capital, the opportunity cost and the associated risk) is taken $10 \%$ which is a mean value between telecom operators. Taxes have not been considered at all, since they vary depending on the country in question and the market conditions.

Table 1. Area Structure And Duct Availability

\begin{tabular}{ccccccc}
\hline \hline Area & $L_{\text {mean }}(\mathrm{m})$ & $D_{s}\left(\mathrm{Km}^{-2}\right)$ & $N_{b}$ & $N_{s b}$ & $D_{1}$ & $D_{2}$ \\
\hline D. Urban & 1400 & 5641 & 1024 & 64 & $90 \%$ & $50 \%$ \\
Urban & 2200 & 2048 & 2048 & 32 & $60 \%$ & $40 \%$ \\
Suburban & 3400 & 410 & 16384 & 4 & $25 \%$ & $25 \%$
\end{tabular}




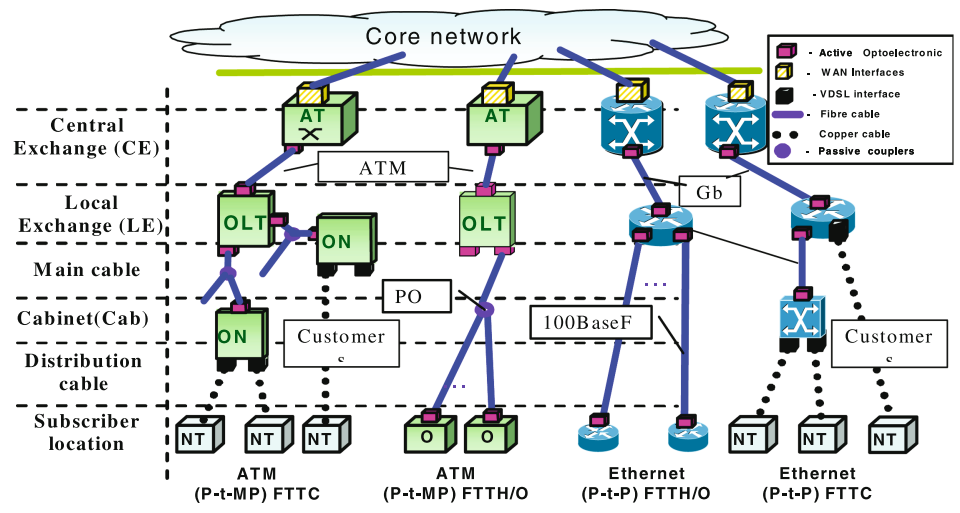

Fig. 1. Generic Comparison Architectures

\section{Technoeconomic Methodology}

The model's operation is based on its database, where the cost figures of the various network components are kept and are constantly updated from data gathered from the biggest European telecommunication companies. The business case is also determined by the broadband services to be provided by the network. This includes the estimation of the market penetration of each service over the study period. The tariffs for the broadband services have to be defined, i.e. the part of the tariff that is attributed to the network under study. From the combination of yearly market penetration and yearly tariff information the TONIC tool calculates the revenues for each year. The broadband access technologies and the architecture of the network to provide the selected service set must be explicitly defined and this needs some network planning expertise. The tool may be used for both wired and wireless scenario evaluation while many network architectures can be accounted for, such as tree, mesh or ring architectures.

To estimate the various infrastructure parameters, such as fiber cable and duct lengths the TONIC tool includes a set of geometric models. These geometric models are optional parts and the TONIC/ECOSYS tool can be used without them, e.g. for radio access technology evaluation, where no geometric models are necessary. The result of the architecture scenario definition is the so-called shopping list. This list is made for each year of the study period and it shows the volumes of all network cost elements (equipment, cables, cabinets, ducting, installation etc.) and the distribution of these network components over different flexibility points and link levels. The costs of the network components are calculated using an integrated cost database. Architecture scenarios are used together with the cost database to calculate investments required for each year.

The future market penetration of the services and the tariffs associated with them, are calculated through market forecasts and are inserted into the tool. The tool also calculates the future price of the various network elements which are needed in the calculation of the Operation, Administration and Maintenance (OA\&M) costs. The price $P(t)$ of each network element is assumed to follow the extended learning curve [11], 


$$
P(t)=P(0)\left[n_{r}(0)^{-1}\left\{1+e^{\ln \left[n_{r}(0)^{-1}-1\right]-\frac{2 \ln 9}{\Delta T} t}\right\}^{-1}\right]^{\log _{2} K}
$$

where the constants $K, n_{r}(0)$ and $\Delta T$ are the learning curve coefficient, the initial relative production volume and the growth period respectively. The growth period $\Delta T$ is the time taken for the total production volume to reach from $10 \%$ to $90 \%$ of its maximum value, while the learning coefficient $K$ is the price reduction experienced when the production volume is doubled. In cases where historical data are available these constants can be determined using ordinary least squares regression. The TONIC tool then calculates revenues, investments, cash flows and other financial results for each year of the study period. The following subsections describe the basic assumptions used in the application of the techno-economic methodology.

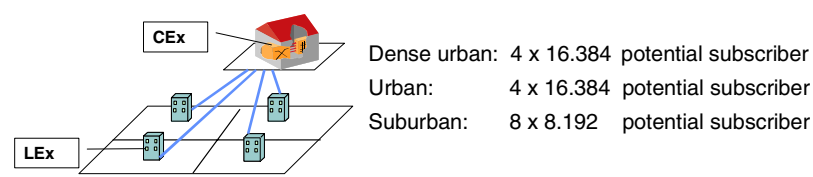

Fig. 2. Example of Central Exchange (CEx) segmentation

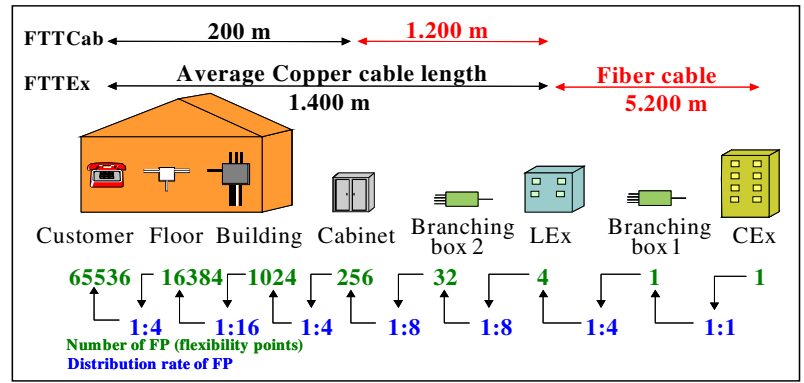

Fig. 3. Distribution Structure and Geographic Model of the Dense Urban Area

\subsection{Area Model and Distribution Structure}

To calculate the fiber duct and cable lengths, each area (dense urban, urban or suburban) is first described in terms of subscriber density, loop lengths, geographical and market characteristics. The area model is based on the Metropolitan Access Network (MAN), starting from the Central Exchange (CEx) and comprising the whole access network all the way to the customers. It is assumed that one CEx serves either four dense urban, or four urban, or eight suburban service access Areas (Figure 2). Dense urban and urban areas under study correspond to 16,384 customers while the suburban area to 8,192 customer units. For each area type, all customers are connected to the same Local Exchange (LEx). The total number of customer units connected via POTS lines to one CEx thus amounts to 65,536 for all scenarios. The parameters of the 
three different areas are summarized in table I in terms of the mean cable length $L_{\text {mean }}$ connecting the subscribe to the LEx, the density of subscribers $D_{s}$, the number of building $N_{b}$, the number of subscribers per building $N_{s b}$, the duct availability $D_{1}$ between the LEx and the cabinets and the duct availability $D_{2}$ between the cabinets and the buildings. The duct availability is one of the most important parameters. It has a strong influence on the economics of the various scenarios due to the high investment costs of ducting systems related to civil works. Figure 3 illustrates the access network distribution structure and the geometric model for the dense urban area. The model has been developed as a total of eight flexibility points (network levels) (FP) and seven link levels (LL).

The cost of digging up trenches, installing ducts and cables, is crucial for the economics of any telecommunications network infrastructure. The geometric model forms the basis for the calculation of very important cost components and it is a fundamental step towards the techno-economic modeling of a telecom investment project.

\subsection{Service and Customer Definitions}

The services to be considered depend on the customer profiles which are classified in Residential and Business customers (including Small and Medium enterprises (SME) and Small Office/Home Office (SOHO)). Key network requirements for business customers are scalability, security, flexibility and differentiated QoS. The range of services required by business customers is wider than for residential customers: file transfer within an Intranet, which means burst traffics and highly variable bit rates, high bit rate access to the Internet and videoconferencing with strong real time constraints. In most cases, these services require higher bit rates than typical residential services. A detailed description of the service definition can be found in 2 .

\subsection{Tariff Structure}

The broadband tariff structure is rather complex. Important tariffs are: connection tariff, access tariff, service provider tariff, traffic tariff, transaction tariff, and charge for content (i.e. pay per view). The tariff model [14] is constructed in the following way: basically it sets a reference tariff (derived from a survey conducted by a number of large operators in Europe) of $720 € /$ year in 2001 for $512 \mathrm{kbs}$ asymmetrical services dedicated residential customers and another reference tariff of 5,280 €/year in 2001 for $512 \mathrm{kbs}$ symmetrical services dedicated to business customers. In addition the model assumes an increase of $17 \%$ for each doubling of asymmetric downstream capacities and an increase of $30 \%$ for each doubling of symmetric downstream capacities in 2002. The model also assumes an annual tariff erosion of $10 \%$. Yearly price erosion of $10 \%$ is applied in addition to the above mentioned tariff increase for transfer rate doubling. A more detailed analysis can be found in [16].

\subsection{Network Switch Model}

In order to calculate the OA\&M costs for each network component, the different switching systems must be modeled. The network element cost model has been built 
based on a switch model containing the parts found in switches of different vendors. These are in general basic equipment including switching fabric, power supply, rack and line interface cards. The model takes into account list price information of several vendors and volume production effects.

Considering the relatively new switching systems and the fact that at the moment these "carrier class" systems under study are at a very early stage of development worldwide, both for ATM and Ethernet systems, it has been assumed that the initial accumulated production $n_{r}(0)$ volume is only $1 \%$. An Ethernet layer-3 switch is installed at the Central Exchange. A detailed description of the switch models can be found in [2].

\section{Influence of the Cost of Photonic Components}

In [2] it has been shown that FTTC solutions for dense urban and urban areas result in advantageous business solutions due to the existing infrastructure. It has also been shown that the total investments for point-to-point Ethernet compared with point-tomultipoint ATM FTTC architectures focusing on both business and residential market are practically of the same value. Point-to-multipoint solutions like GPON become more interesting when considering FTTH residential scenarios and have been compared to point-to-point solutions advantages when capacity demand is limited and distribution ratio is high. All together the authors believe in a future heterogeneous solution where both point-to-point and point-to-multipoint solutions are able to sustain their specific advantages. But the further evolution of FTTC architectures to the FTTH/O architecture in the future can be economically viable only if the market becomes mature enough for such high-speed data transfer rates. This is due mainly to the tariffs and customer penetration but the equipment cost is also an important factor.

The Net Present Value (NPV) and the Payback period can be used as financial measures in the evaluation of telecom investment projects. To estimate the importance of the various parameters (such as equipment cost, etc), one can carry out sensitivity analysis in these measures. Sensitivity analysis is carried out by calculating these measures and varying one single parameter while keeping all the other parameters constant. The sensitivity results can be used to identify and rank the most critical parameters in the investment project. Figures 4(a) and 4(b) show the NPV for both the FTTC and the FTTH/O Ethernet deployment scenarios in dense urban areas respectively. The parameters varied are identified in the left of the bar figures. As shown in figure 4, the NPV for the FTTC basic scenarios is $30 \mathrm{M} €$ and much higher than that of FTTH/O (8M€) which is to be expected mainly because of the increased cable installation cost in the latter scenario. Both business cases however have a positive NPV.

From the FTTC NPV sensitivity analysis in figure 4(a) we observe that for a $20 \%$ increase in the total penetration the NPV rises as high as 37M€, implying an increase of $23 \%$ in the total investment value. Figure 4 also shows that in both FTTC and FTTH/O architectures the price evolution for the components is important. Unfortunately however, even in the case that the prices within a ten years period fall down to the $33 \%$ of the 2003's level, the deployment is mandated mainly from economical and not from technological factors. This is due to the fact that technology 


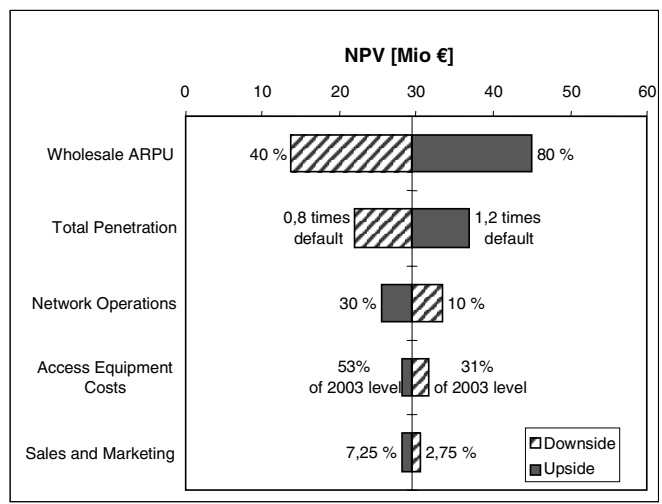

(a)

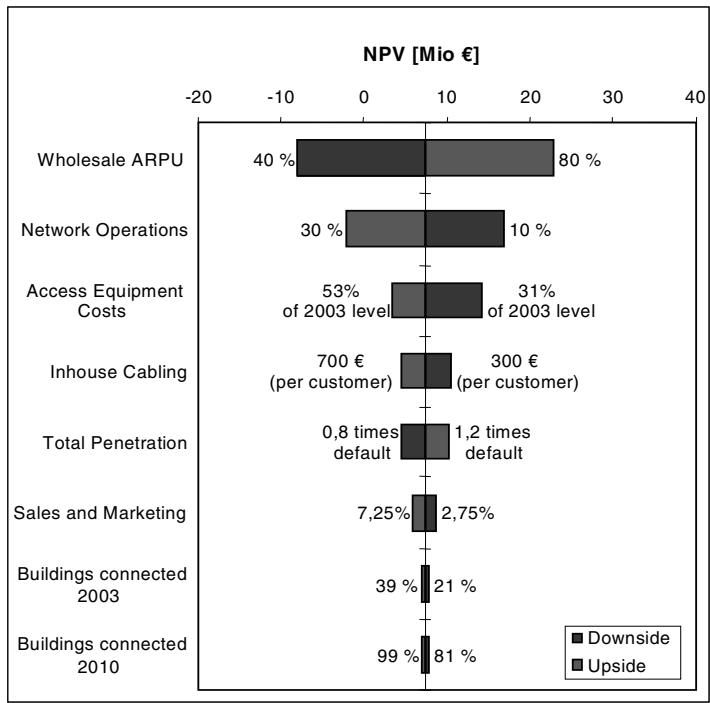

(b)

Fig. 4. Access equipment cost evolution is more highly critical for FTTO/H deployment (b) than for FTTC architectures (a). ARPU=Average Revenue Per User.

(especially optoelectronics) contributes less to the overall investment cost even in the FTTC scenario. This is better illustrated in figure 5, where the contribution of each cost component to the total investment cost is analyzed. As seen the labor/installation costs contribute as much as $62 \%$ to the overall and hence expenditures are mainly dominated by this factor. In suburban areas, this cost contribution will be even higher and hence even more unfavorable figures are to be expected in this case.

Although the price of photonic components seems to be a secondary factor influencing the business case, one should keep in mind that part of the overall expenditures are 


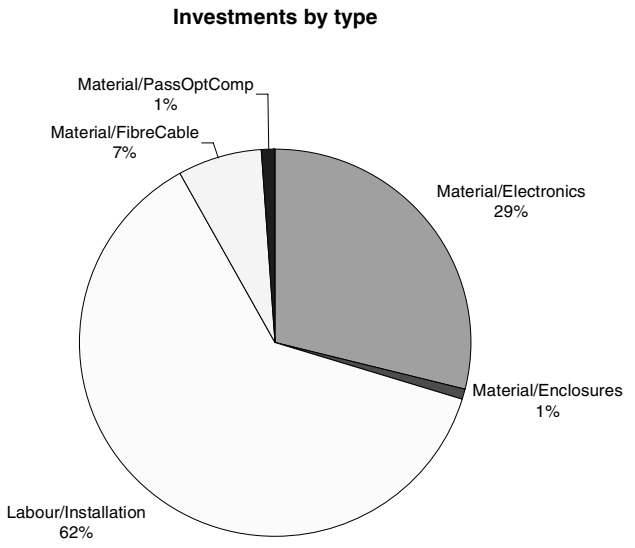

Fig. 5. Investments per type. The main costs are due to installations and electronics in FTTC.

related to OA\&M costs which are related to the price evolution of the telecom equipment. It is therefore more interesting to investigate the sensitivity of the various economic figure of merits with respect to the quantities related to the price evolution of photonic components and hence the maturity of the PCI.

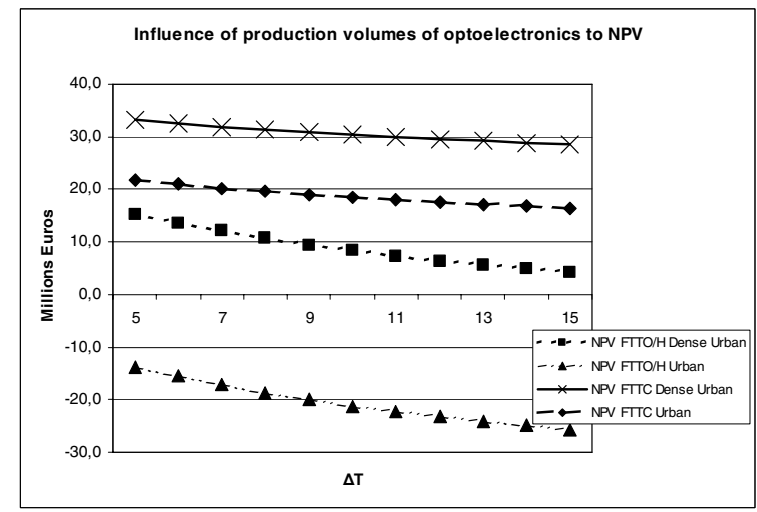

Fig. 6. Relation between the NPV and the $\Delta \mathrm{T}$ parameter of photonic components

This is demonstrated in figure 6, where the value of the NPV is plotted for both FTTC and FTTH/O in the case of urban and dense urban areas with respect to the parameter $\Delta T$ of the optical components. As $\Delta T$ is increased, the rate of increase of the production volumes of optical components is reduced and the NPV drops. Comparing the slope of the curves, it is deduced that the deterioration is more severe in the FTTH/O scenario. In the dense urban case, the NPV is reduced considerably but remains marginally positive. In the urban case, the NPV attains even smaller values, thereby seriously undermining the value of such a business alternative. The slope of the curves 


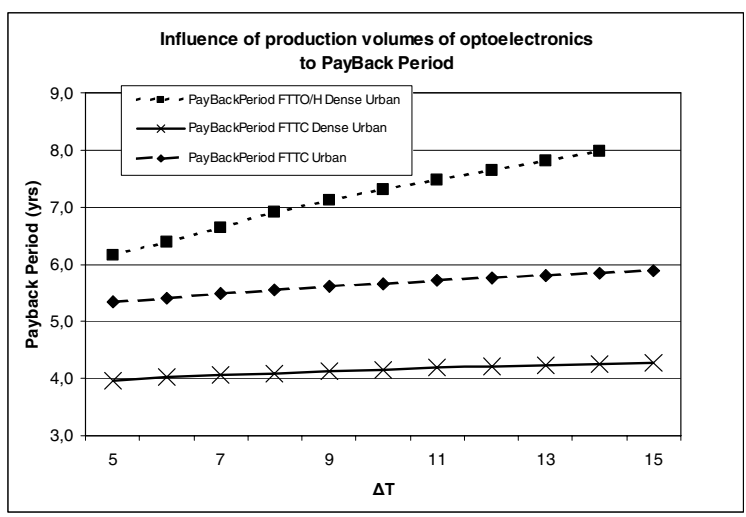

Fig. 7. Relation between the IRR and the $\Delta T$ parameter of photonic components

indicates that major improvements in optoelectronics technology may benefit the deployment of FTTH/O to urban and suburban areas and will hurdle the labour and installation costs.

Figure 7, illustrates the Pay Back Period (PBP) as a function of $\Delta \mathrm{T}$ for the three scenarios with positive NPV. In the case of FTTC, $\Delta T$ does not seriously change the $\mathrm{PBP}$ in the dense urban case, while its impact is more noticeable in the urban case. As expected the PBP in the dense urban FTTO/H scenario is more intimately related to $\Delta T$. A slow down of the photonic component industry by 10 years (from $\Delta T=5 y$ rs to $\Delta T=15 \mathrm{yrs}$ ) can add 2 years in the expected PBP of the investment. Since the new optoelectronic components are not mature yet, they will likely have uncertainty in their price evolution. The influence of this factor in percentage values is quite large due to the fact that optoelectronics represent the majority of investments in the project, except labour/installation costs.

\section{Conclusion}

In this paper a methodology for determining the impact of various key factors influencing the economic viability of metro/access optical network upgrades was presented. The prospects of both FTTC and FTTH/O deployments based on Ethernet technology from the viewpoint of an incumbent network operator were considered. The business cases studies show that the success of the FTTC and FTTH/O deployments are determined mainly from economic and market issues (tariffs, demand) rather than technological ones. Existing technology was shown to favor investments in dense urban areas and particularly FTTC. FTTH/O results in longer pay-back periods and should therefore wait for a either more mature market or technological improvements, or otherwise operators must accept longer Pay Back Periods. Investments in photonic component technology can lead to shorter payback periods and consequently, additional cash flows. These cash flows could be used for further investments in order to provide advanced broadband services to end users especially in urban and suburban areas as well as to other areas in general. Since price evolution of components is not linear and rather logarithmic with 
respect to production volumes, mass production of optoelectronics can turn unfavorable cases to successful ones. In conclusion, investments in technology can develop new values besides the traditional ones adopted by the operators, which are based mainly on new service development and operational cost savings.

Acknowledgement. This work was co-funded by the European Social Fund \& National Resources under a EPEAEK II- PYTHAGORAS grant. Authors would also like to thank their partners in IST/TONIC and CELTIC/ECOSYS projects.

\section{References}

1. Organisation for Economic Co-operation and Development http://www.oecd.org/ document/9/0,2340,en_2649_37441_37529673_1_1_1_37441,00.html

2. T. Monath, N. K. Elnegaard, P. Cadro, D. Katsianis, and D. Varoutas, Economics of fixed broadband access network strategies, IEEE Commun. Mag., 41, 132-139 (2003).

3. N. J. Frigo, P. P. Iannone, and K. C. Reichmann, A view of fiber to the home economics, IEEE Commun. Mag. , 42, S23 (2004).

4. R. Van Caenegem, J. A. Martinez, D. Colle, M. Pickavet, P. Demeester, F. Ramos, and J. Marti, From IP over WDM to all-optical packet switching: Economical view, J Lightwave Technol, 24, 1638-1645 (2006).

5. E. Le Rouzic and S. Gosselin, 160-Gb/s optical networking: A prospective technoeconomical analysis, IEEE J. Lightwave Technology, 23, 3024-3033 (2005).

6. J. Livas, Optical transmission evolution: From digital to analog to network trade offs between optical transparency and reduced regeneration cost" IEEE J. Lightwave Technology, 23, 219-224 (2005).

7. S. K. Korotky, Network global expectation model: A statistical formalism for quickly quantifying network needs and costs IEEE J. Lightwave Technology, 22, 703-722 (2004).

8. E. Chen and D. Lu, The economics of photonics manufacturing, J.P. Morgan $H \& Q$ Equity Research (2001).

9. D. Varoutas, D. Katsianis, T. Sphicopoulos, F. Loizillon, K. O. Kalhagen, K. Stordahl, I. Welling, and J. Harno, Business opportunities through UMTS-WLAN networks, Ann. Telecommun., 58, 553-575 (2003).

10. D. Katsianis, I. Welling, M. Ylonen, D. Varoutas, T. Sphicopoulos, N. K. Elnegaard, B. T. Olsen, and L. Budry, The financial perspective of the mobile networks in Europe, IEEE Pers. Commun., 8, 58-64 (2001).

11. EU TONIC, Techno-economics of IP Optimised Networks and Services, IST-2000-25172. Available at http://www-nrc.nokia.com/tonic/

12. ECOSYS, techno-ECOnomics of integrated communication SYStems and services, Available at http://www.celtic-ecosys.org/

13. T. P. Wright, "Factors affecting the cost of airplanes," J. Aeronautic Science, 3, pp. 122128 (1936).

14. K. Stordahl, L. A. Ims, M. Moe, "Broadband market - the driver for network evolution", Proc Networks 2000, Toronto, Canada, September 10-16 (2000).

15. K. Stordahl, L. A. Ims, N. K. Elnegaard, F. Azevedo, B.T. Olsen, "Broadband access network competition - analysis of technology and market risks", Proc. Globecom '98, Sydney (1998).

16. D. Varoutas, C. Deligiorgi, Ch. Michalakelis and T. Sphicopoulos. "A hedonic approach to estimate price evolution of telecommunication services: Evidence from Greece", to appear in Applied Economic Letters, Taylor and Francis. 